\title{
CLAROSCURO DE LA PROVINCIA Y EL ARRABAL: ENRIQUE LABRADOR RUIZ
}

\author{
POR \\ JULIO MATAS \\ University of Pittsburgh
}

Labrador Ruiz es, entre nuestros hombres de letras, el único gran humorista de la vida cubana; tengo por verdadero humorista de una sociedad a quien sabe trazar piadosas caricaturas de sus componentes, por ver en ellos hechuras, cuando no víctimas, de tradiciones e instituciones de un modo u otro siempre opresivas o mutiladoras. De esta especie de humorismo han sido maestros Dickens, Gogol, Galdós.

Los ambientes que recoge Labrador Ruiz se nos presentan como vistos a través de un cristal que los agranda y deforma. Mucho tienen sus relatos de capricho goyesco o esperpento valleinclaniano; atrae en ellos, primeramente, el brillo, la gracia del artificio y no la pura experiencia (o su trascendente significado). En otras palabras, lo que caracteriza las narraciones de Labrador Ruiz es lo que poseen de grabado o grabación de tipos, giros lingüísticos y modos de pronunciación (algo así como un aguafuerte de imágenes verbales); esa retórica suya, no siempre fácil —el lector de su obra ha de aguzar sus facultades de percepción-, vuelve paladeables (magia del arte), en sus relatos, las numerosas variantes de la chabacanería nacional, caldo del escarnio, el timo, la poltronería y las reputaciones de similor. Labrador Ruiz llama, por cierto, a los cuentos de El gallo en el espejo, «espesas estampas», añadiendo que «dan la medida de un rastreo en nuestro carácter» ${ }^{1}$.

Naturalmente que no se puede hablar de narración propiamente dicha

${ }^{1}$ Cito por El gallo en el espejo (Lima: Organización Continental de los Festivales del Libro. Primer Festival del Libro Cubano, 1958), p. 7. Utilizo esta edición para las citas correspondientes a «Cinqueños» y «El gallo en el espejo», dando en el texto, en paréntesis, el número de página. 
si no se presenta en ella un conflicto, aunque sólo sea el que se desarrolla en el interior de cierto personaje o personajes. Sin conflicto, aquellas «espesas estampas» no pasarían del cuadro de costumbres. No falta en ellas, en consecuencia, una más o menos intensa «agonía». Y es que sus protagonistas, ingenuos, sensibles, pródigos de caridad y, por lo regular, contraventores de la norma social, constituyen ejemplares acabados del orden patético, de un pathos que no lo es menos por el aire grotesco que ostentan tanto los personajes como sus respectivas realidades. No sorprende, pues, que el destino que comparten varios de aquéllos, como veremos en el estudio textual que sigue, sea el de ese definitivo sobrepasar la trama de lo inmediato, que es la locura ( $« . .$. lo que arrastra a la locura es precisamente la razón», apunta, por cierto, Labrador en «El pedicuro») ${ }^{2}$.

Una buena parte de los relatos de Labrador — «Tu sombrero», «El pedicuro», «Nudo en la madera», «Reparada», «Aquellas personas», «Cinqueños», así como aquellos que integran el gran mural de La sangre hambrienta ${ }^{3}$ - nos ofrece tal vez la visión más morosa, más minuciosa, más atenta al pormenor de decires, quehaceres y modos de ser de nuestros pueblos entre cuantas obras de uno $\mathrm{u}$ otro género se han escrito en Cuba sobre la vida provinciana. No me parece, en todo caso, que ningún otro autor cubano haya logrado elevar la provincia a categoría estética como lo ha realizado Labrador. Me concentro aquí, para ilustrar lo que sostengo, en «Cinqueños», aunque bien podría haber escogido otro relato (me atraen particularmente «Nudo en la madera» y «Reparada»).

«Cinqueños»es, a grandes trazos, un compendio de la murmuración pueblerina..., «esa terrible habladera de pueblo que no deja hueso sano; ese chismorreo de puerta de iglesia; los murmullos de barbería, de rebotica»... (p. 11). Así considerado, se impone su carácter de relato ejemplar, en el sentido cervantino, esto es, sin evidente moralización, pues el texto se desarrolla en circunvoluciones de ironía que iré señalando en el curso del examen que sigue.

Como se recordará, el protagonista del relato, el carpintero Agustín Viera, vive obsesionado por el hecho de que sus hijos, una hembra y un varón, hayan nacido «marcados» con un sexto dedo en las manos, por ser dicha «marca» una característica del primer marido de su mujer, de quien se había separado ella mucho antes de su encuentro con Agustín. Para Agustín, tal «marca» es una mácula sobre su honor, no importa cuán remota o absurda sea la sospecha sobre la fidelidad de Gloria, su mujer,

\footnotetext{
${ }^{2}$ Edición citada, p. 41.

${ }^{3}$ No puedo llamar novela a La sangre hambrienta. Me parece más bien una colección de relatos que comparten el mismo escenario, al modo de Winesburg, Ohio, de Sherwood Anderson.
} 
ya que aquel hombre no vive en el pueblo desde hace años. Agustín vive atormentado por «celos retrospectivos», exacerbados por el acicate del rumor popular. La habladuría, el chismorreo, constituye en realidad una suerte de antagonista con el cual lucha Agustín y al cual irónicamente vencerá sólo al perder la razón, justo en el momento en que cree haber encontrado, nuevo matiz de ironía, la «científica» razón de aquel fenómeno que lo aflige.

Labrador construye su relato, si bien se mira, a partir de un chisme que pide «a gritos» la comunicación; la narración misma se convierte, así, en un prolongado cotilleo, el cuento de un chismoso de oficio que, a la vez que indirectamente condena, participa de lo que el narrador llama, a propósito de las viejas habladoras que interpelan a Tinito, el hijo de Agustín, «el bizcocho de la palabrería» (p. 9). Si se trata de palabrería, parloteo con hirientes insinuaciones, aquello es también, a fin de cuentas, bizcocho, golosina que tienta a todos con su sabrosa malicia. Obsérvese, para confirmación de lo que apunto, el tono de cronista de casino o cotarro de café que adopta el narrador en el párrafo inicial del relato:

Nadie en el pueblo se había atrevido jamás a develar siquiera por el forro el misterio de los cinqueños - la hembra y el varón-; los buenos tipos hijos de Agustín Viera, con los ojos azules de la madre, pero no grandes, sino más bien ojuelos de paloma, con la estatura mayor del padre y ese aire resuelto de estar siempre a la defensiva. Mas de la hembra ya no debe hablarse porque murió sin saberse de qué. Ahora sólo queda el varón, el testigo público e inocente para contradecir en un punto los perfectos amores progenitales. ¿Que cómo digo? Como lo estoy diciendo y en el pueblo esto era un escándalo, una soterrada y comprometida evidencia, aquello que denuncia y no denuncia pero denuncia; lo que da ganas de murmurar y se pretende evidenciar a bien que no es bueno insistir en ello porque ¿cómo será posible? ¿Y hasta dónde lo posible entra aquí si lo imposible está de por medio y como si se dijera fuera de todo chance concreto y real? ¡Oh!, si fuera algo obrado por potencias, eso es, por potencias... (p. 7):

Lo que se destaca en el texto transcrito es, sobre todo, el deseo de hablar, expresado negativamente primero con la frase de la hembra ya no debe hablarse, pero enfáticamente reafirmado en el ¿Que cómo digo? y el Como lo estoy diciendo que lo sigue, hasta alcanzar el clímax, iniciado con lo que da ganas de murmurar y que finaliza con el párrafo. (Por cierto, este párrafo sirve de introducción al mencionado diálogo de las comadres.) De este modo, puede asegurarse que lo sobresaliente del relato es precisamente el poder de la palabrería, murmuradora o explicativa: esos trozos 
de conversación mediante los cuales nos imponemos, con puntos y señales, de los antecedentes del «caso» o de su aparente resolución hacia el final (el diálogo con el nuevo médico del pueblo, del cual me ocupo en seguida).

El texto se mueve así, como el desdichado Agustín, de la charlatanería insinuadora a la befa de la locura, Escila y Caribdis de la murmuración pueblerina. La gran vuelta de ironía del relato es justamente esa explicación «científica» del joven médico, a la cual me he referido antes. El médico expone su explicación - nos dice el narrador-con «aire romántico» (p. 15); se trata de un médico todavía inexperto, a falta de una clientela en quien practicar su arte, pero, lo que es peor quizá, de un médico literato o libresco — se nos informa que pasaba las noches leyendo-, aficionado tanto a las «letras» como a «románticas» fantasías. Lo paradójico es que el médico hable movido, principalmente, por la caridad; desea «ilustrar» a Agustín para así calmar su desasosiego, a sabiendas de lo que el pueblo rumorea. Ahora bien, el eufemismo culto que se le ocurre para atenuar la crudeza de su disertación sobre caprichos genéticos obra su efecto liberador con exceso: aquella palabra, telegonía, se convierte en clave de la seráfica demencia de Agustín... «iPero calcule usted — se dice Agustín esa nochesi una palabra tiene que ver! Si lo puede salvar a uno del presidio y, lo que es mejor, de la injusticia más tremenda. ¿Que Dios me perdone!» (p. 19).

Otros pasajes que dan cuenta de la incesante parlería del pueblo sirven adecuadamente para introducir algún rasgo de importancia: la habladuría sobre las lecturas nocturnas del médico, que apuntan a su «rareza» (se dice que es aún estudiante, porque se le ve leer de noche), o el diálogo sobre un hecho de sangre, que evoca la violencia comunitaria, al mismo tiempo que subraya la pasión cruenta de Agustín (Agustín sueña en cercenar las excrecencias de sus hijos o en matarlos junto con su mujer). Cito ese último diálogo, que escuchan (como fondo de escena) Agustín, su cuñado Gumersindo y Tinito cuando van camino de la casa del médico:

-Si ya lo pelaron al moñito, ¿pa qué ocuparse del cerquillo?

Otro decía superficialmente:

- Le pasaron un pernil de un balazo. ¿Tú crees que el médico nuevo ni ningún médico pué hacer na ahí?

- Guayabita, te portas como lo que eres. ¿Qué es eso de pernil? Se dice mur-lo. ¿Oyes bien? El mur-lo.

-Lo que sea; ya está dicho. El balazo le cogió la funeral.

Quería decir la gran arteria femoral.

Guayabita ratificó que de «pernil pasao» nadie escapa, según le consta, aun cuando esté bien lleno de grasa. Si habrá visto él muertes en su vida... (p. 14). 
El comentario del narrador, de inmediato transformado en discurso indirecto libre en el párrafo que sigue, otorga un especial sentido a aquel sangriento paso de comedia, pues nos permite apreciar la correlación entre la crueldad colectiva y la personal, o, mejor, ver el origen de esta última en la vieja tradición hispánica que ordena, para gozar de público respeto, derramar sangre ajena como vindicación de pretendidas ofensas y deshonras:

Esta escena de sangre, bien poco común en el pueblo a no ser en época de elecciones, llenó su corazón de remordimientos. Eso hubiera querido hacer alguna vez con su mujer y sus hijos, enardecido como estaba con aquella nefasta reiteración del dedo supletorio, que se reía de él, que se mofaba de su honradez. ¿Por qué el destino le infería tal herida de fuego, tal seña ostensible, tal marca desatinada? Y si todo era humo de pajas, ¿por qué perdía la cabeza y soñaba con sangre expiatoria? «iSan Pedro, sácame de este berenjenal!» (p. 14).

El modo grotesco, de bufonada trágica a que aspira, en general, el arte narrativo de Labrador, alcanza en este punto, como puede observarse, forma muy particularmente lograda. El diálogo es, por último, otra vez, el recurso favorecido por Labrador, para proyectar la nota de comedia, con ribetes de choteo criollo, a propósito del arrebato de locura de Agustín. Véase, primero, el intercambio verbal de Agustín con un compañero de trabajo, el negro Socarrás, incluido el «aparte» interior de éste:

-Pues sé por qué tiene Tinito eso en su mano - dijo al negro Socarrás, quien metía los zunchos de hierro en la gran fornalla de tierra para que se dilatasen y poderlos ceñir a las ruedas de las carretas-. Ya lo sé. iTelegonía!

—Tele ¿qué? ¿Con qué se come eso? (p. 18).

- Siempre te he visto como piojo en costurita — pensó el negro--; este asunto de tu mujer te va a volver loco. Y tu mujer, que debe ser como quimbombó en plato llano... contenta pa que te acabe de ig pal demonio. La muy rebalosa se afiló las uñas» (p. 19).

La versión del trastorno, que da Caguagua - el dueño de la carretería donde trabaja Agustín - a la familia, al traerlo a la casa, revela el carácter de la locura de aquél (transcribo también el párrafo narrativo que introduce el diálogo): 
Mas llegan a la casa voces entrecortadas. ¿Qué sucede? Caguagua, el dueño de la carretería, relata en un haz confuso la extraña conducta de Agustín, el intento de agresión al negro Socarrás, los besos que ha dado en el filo de su azuela, las veces que ha repetido una corpulenta palabra con cierto tono desertor.

- Ni siquiera Gumersindo ha disparado un chícharo en toa la mañana. $\mathrm{Y}$, además, ha estao como rezando.

— ¿Qué cree usted?

- $\mathrm{Na}$, que se nos ha vuelto un pico de oro. Ha estao echando sermones y hablando de la caridad y la misericordia como si fuera un padre predicador. Llamen al méico, a ver qué tiene (p. 20).

Es una quijotesca manía evangélica que, sin duda, dará de nuevo mucho que hablar; ninguna habladuría, sin embargo, podrá turbar ya la tranquilidad de Agustín, hacer mella en esa providencial enajenación.

Las intervenciones de Tinito con que se cierra el relato resultan, por ello, como la voz de la pedantería vulgar, de la seudociencia callejera, resumen de la más pedestre indiferencia ante el significado moral del trastorno de Agustín. Se refuerza, de este modo, el juego de sombras y luz, de grave esencia y circunstancias de sainete, que caracteriza no sólo la situación, sino la narración toda:

-Eso de nosotros..., que es un asunto de radio. O de telegrafía sin hilos, o de televisión. ¡Hombre! ¿Quién no sabe lo que es telegonía? Si es lo más fácil del mundo.

Y volviéndose a su padre, con gran aplomo:

-Papá, descansa. No te va a pasar nada. La marca de fábrica era falsa (p. 21).

Si en general, respecto a las narraciones de Labrador Ruiz, se puede hablar, como sugiero a propósito de «Cinqueños», de un juego de luz y sombra, «Conejito Ulán» ${ }^{4}$ constituye el más acusado claroscuro. Claroscuro de vida y muerte, de realidad e irrealidad, de pasión y represión, esterilidad y fecundidad, cordura y delirio. El escenario escogido por el autor para este drama de una existencia devorada por su propio fuego no podía resultar más adecuado: no es ahora el pueblecito de la inacabable murmuración, sino el arrabal rústico de la ciudad, en este caso la propia capital. En una de esas finquitas de las afueras, «el conuco cerca de La Habana» (p. 123), con su escasa vida social por carecer de un centro - la proximidad a La Habana hace que las ocasionales expansiones se trasladen

${ }^{4}$ Cito por Carne de quimera (Novelines neblinosos) (La Habana: s.e., 1947). Doy número de página de esta edición, en paréntesis, en el texto. 
allá-, el destino de la protagonista está ya prefigurado. Porque el drama de Maité es, en principio, más que el de la soltería - ésa será la «fatal» consecuencia--, el de la soledad, mejor aún, el de quien sigue, de grado o por fuerza, el apartamiento del mundo al estilo ermitaño. El hecho es que Maité se ha impuesto, por motivos que expongo en breve, los rigores de una virgen solitaria, renunciando, de paso, a las exigencias de una naturaleza saludable y tierna, sensual a la par que maternal. El «conuco» viene a ser, así, su refugio en el yermo, el inaccesible huerto de sus trabajos y devociones. Esas devociones, aunque no exactamente religiosas, de algún modo lo son, pues se trata de una absorbente piedad filial, más bien la incuestionable reverencia que Maité cree deber al padre muerto. Y por ahí entramos en la causa profunda de su ev̀entual desvarío.

De las cuatro partes en que Labrador divide el relato, la primera está dedicada precisamente a perfilar la imagen del padre o, mejor, a evocar aquella sombra que se cierne agoreramente sobre la vida de la hija. Fue el padre, para empezar, quien, «muerta su propia mujer, encerróse en el conuco cerca de La Habana, muy bonito con sus tablas de yuca, su punta de maíz y la hortaliza que era un contento» (p. 123). Su conclusión acerca de aquel retiro, indirectamente transcrita por el narrador, es especialmente significativa: «Poca cosa, pero ¿qué más quería para ellos solos?» (p. 123). Dos párrafos más abajo se nos informa, además, del carácter insociable del padre:

Tuvo su padre siempre muy mala voluntad a los vecinos, especialmente a aquellos de su tiempo que no hicieron la guerra como él. Los llamaba despectivamente «pacíficos», cuando no cargaba el acento en lo de «guerrillero» y demás abominaciones que se le venían a la lengua.

Este bizarro mambí, que no perdona a quienes no lo han sido (ni poseen su heroica madera) y que impone en su casa una tiranía de rey guerrero, cobra, a los ojos de Maité, la magnitud de un Agamenón. «Picado por la viruela -nos dice el narrador-, el rostro de su padre era imponente» (p. 124). Maité, por otra parte, se nos antoja una apasionada Calipso a quien se hubiera obligado a asumir el papel de Electra o casta Diana (señalaré en su oportunidad la semejanza de Maité con otra figura mitológica). Imaginamos, en fin, el rostro rugoso del padre imponiendo mudamente a Maité obediencia o sumisión a sus creencias y manías. Antes de morir, todavía más, el viejo hace a Maité esta advertencia, que tendrá para ella valor de mandato divino: 
- Hija mía: nunca te cases con «pacíficos»; ya sabes cómo me caen. Pero si no encuentras un veterano, un veterano de verdad, por lo menos que sea gente macha. No quiero, ni muerto, en mi familia, flojos o arrastraos... ¿Qué vainas! ¡Valiente calamidad! (p. 124).

Aclara a continuación el narrador: «Por oír y obedecer este consejo, Maité quedó soltera» (p. 124). Se sugiere también, de modo más o menos explícito en este primer segmento, cómo Maité ha refrenado sus verdaderas inclinaciones - las procreadoras y criadoras - en honor a su padre:

Aviando el anafe para la plancha, sintió ganas de regalar juguetes a no sabía cuáles niños: muchos juguetes. Algo no previsto la tornaba tierna y maternal (p. 126).

A veces sentíase renacer con vivo ímpetu, se llenaban de fuego sus venas, le sudaba un poco el labio superior y mirándose al espejo se hacía concesiones piadosas: «Si todavía llegase alguno con vergüenza. Si todavía, un hombre, lo que se llama un hombre...» (p. 127).

Estas ambigüedades le traían a considerar que si se hubiese unido a un hombre, pues ahora..., ahora las cosas no serían así. Porque un hombre, si éste es bueno y entero como debe ser, pues siempre viene bien y compone y arregla las malezas del cuerpo y del alma y los estropicios de la tierra y hasta del cielo. «De verdad - concretó-; no hay otra mejor verdad» (p. 128).

Aun la acción de Maité de espantar el chichinguaco, «que come la garrapata a los bueyes», alcanza un valor simbólico que refuerza lo que se nos va comunicando sobre sus sentimientos y lucubraciones. «Lo cierto es que le repugna y no quiere el espectáculo ante los ojos», indica el narrador. «iFuera, totí feo, fuera!» — grita Maité a los pájaros, y agrega-«Comiendo bichos vivos»... (p. 127). Maité siente una incontrolable repulsión al ver a aquellas aves devorando otras criaturas; se trata de una reacción inconsciente a un acto justamente opuesto al instinto reproductor. El totí o chichinguaco, que impide la proliferación de los insectos, aparece vagamente para Maité como una fuerza destructora de lo creado y viviente; Maité obra, en definitiva, como la buena madre de las criaturas que están a su cuidado, o en su proximidad:

Sólo que su buen corazón se compensaba con los animalitos, cosa que es, según se dice, como doblar a lo bueno por atajo. ¿Qué manera de tenerle ley a los animalitos! No hubo pájaro alirroto, perro con moquillo, caballo con muermo ni vaca con cangrina o mazamorra que ella no curara enérgica- 
mente. Piantes y mamantes dábanle infinita lástima, y el aceite de ricino, las hojas de yagruma, raíces de mastuerzo y otros remedios, hubo temporadas que se movieron tanto de la casa al corral como jícara en velorio (pp. 125-126).

Por esa vía le llega a Maité, a la postre, el castigo agridulce que su propia naturaleza traicionada le propina. Labrador, de manera admirable — «Conejito Ulán» es, a mi juicio, el mejor de sus relatos-, nos introduce, en la sección II, a la desvariante pasión de Maité sin transición o aclaración previa. Nos adentramos así, de golpe, sin preámbulo (las explicaciones, llenas, no obstante, de deliciosas ambigüedades, vendrán después) en la exaltación amorosa de Maité o, por mejor decir, en el mismo centro de su delirio, en aquel espacio imaginario proyectado por su vitalidad largamente contenida. Son las palabras de Maité, por lo demás, las que inician el pasaje: «-Me se pierden las manos — reía ella-. Apenas me las hallo. ¡Tan contenta estoy! Contenta»... (p. 128). El narrador comenta a continuación: «No salía de su asombro, teniendo buen cuidado en disimularlo. ¡Oh! Ulán, con su bozo rubio, señorea la casa!» (p. 128). Sigue una larga descripción de este extraño Ulán y de la no menos extraña o sorpresiva manera en que llega a compartir la cama de Maité, descripción interrumpida ocasionalmente por las reflexiones de ésta. La descripción es intencionada: Ulán recuerda, por su comportamiento, a un animal, y ciertos indicios apuntan, con más precisión, a los rasgos físicos y de carácter de un conejo, incluidos la «viva elocuencia reproductiva y una indiferencia absoluta con respecto a la cronología de su prole» (p. 129), y sus gustos y disgustos alimenticios (odio a las carnes y preferencia por los nabos y remolachas de la huerta).

La visita de la guardia rural sugiere, por otra parte - de nuevo, luz entreverada de sombras-, que en el inconsciente de Maité se ha producido un curioso desplazamiento, pues los soldados inquieren por un tal Ullán o Julián (el nombre del famoso vengador por quien fue «forzada» España no me parece casual en escritor de frecuentes referencias cultas como Labrador), un pillo a quien describe el cabo como «Bajito; con el labio partío»... (p. 131). La ambigüedad creada se hace mayor al puntualizar el narrador que Ulán se había colocado detrás de la arpillera de yute» (p. 131). ¿Existe ese Ulán del labio leporino, cuya figura atrajo a Maité al verlo en algún momento? ¿El Ulán que se esconde tras la arpillera no es más que el conejo a quien Maité ha dotado de cualidades humanas? Sólo a partir de la sección siguiente del relato se podrá optar, siempre con reservas, por respuestas afirmativas. Cabe también suponer que los guardias vienen a ver a Maité alertados por los vecinos acerca de su conducta (tal vez sus protestas de amor a Ulán se han proferido en tono demasiado alto); 
lo cierto es que los guardias se alejan de la casa con «esta certeza absoluta: "Está perdía"» (p. 132).

El colmo de la disparatada felicidad de Maité es, sin duda, su asombrosa -repentina y prolífica - maternidad. «En breve tiempo, en menos que zumba un mosquito, en menos que canta un gallo..., pues, ¿cómo diré?, surgieron cinco varones»... (p. 132), cuyos nombres - Labrador hace aquí un guiño al lector cubano, familiarizado con cierto folclore volanderoson réplica de los «cinco hijos» de una vieja guaracha: Pedro, Pablo, Chucho, Jacinto y José ${ }^{5}$. Hijos de la fértil imaginación de Maité, ostentan la marca inconfudible del «padre» en el labio hendido. «Eran cinco soles que en el firmamento mustio de Maité - anota el narrador - brillaban con esplendor inusitado» (p. 133).

El lado sombrío de esta plenitud luminosa viene dado, en primer lugar, por la evocación del padre tirano, a quien Maité trata de aplacar con muestras de amor o de espantar con ofrendas supersticiosas:

Lo cierto es que en ocasiones la memoria del veterano se levantaba furiosa: «No quiero en mi familia, ni muerto, pacíficos o...» Temblaba Maité y se decía: «Tendré muchas flores este año para su aniversario; no se va a quejar» (pp. 128-129).

Un viento malo que sopla por aquella vuelta de un tiempo a esta parte, trae la sombra del veterano, quien por encima de la cerca de piedra se pone a maldecir con virulencia de lo que siempre maldijo y de si, ni muerto, quería para su hija...

- ¡Sola vayas! — vocea Maité por las lechuzas que salen de su nido y por algo secreto que le daba calofríos-. Voy a encender una vela al ánima sola..., pa que descanse (pp. 130-131).

La sombra surge, en segundo lugar, de la propia Maité, que, al igual de una heroína trágica, posee una debilidad que la pierde o, más bien, que le hacer perder a Ulán (vista por el revés, su debilidad, en definitiva, le hará perder su sueño, el delirio de su pasión). «Femenino instinto», la llama el narrador: es la adivinación del punto vulnerable que puede servir para dominar al amante, para hacerle sentir la necesidad de la protección que ella entonces ofrecerá. Cuando Maité descubre que Ulán se aterra al «sentir perros atraillados» (p. 133), le asesta una puñalada metafórica, cuyas consecuencias habría de sufrir ella a la postre: «con cruel regocijo»,

${ }^{5}$ Obsérvese el humor que rezuman las líneas siguientes, con la «implacable sorna» del viento y la referencia inmediata al canto popular: «Con implacable sorna el viento devolvía estos nombres, y algunos canturrieros de la zona se obstinaron en sacarle brillo a fuerza de repetirlos, con música y todo» (p. 132). 
se nos dice, Maité le dirige la siguiente burlona pregunta: ${ }_{i} \mathrm{O}$ es que se te antoja, bribón, irte de cacería?» (p. 134). El encantamiento en que vive Maité se romperá precisamente al son de una cacería: «Esta fantástica existencia vino a quebrarse cierta madrugada en que se oyeron por la trocha del fondo tiros dispersos, perros atraillados» (p. 140).

Se sugiere de este modo, con la evocada presencia del padre, que la cohíbe, y con la «falta» - hamartía - de Maité, una fatalidad que nos hace pensar en el curso a la vez obligado y natural de la antigua tragedia. Más aún: en Maité parece reencarnar alguna de aquellas figuras de mito, admiradas y abominadas por una extraordinaria aberración, en particular Pasifae, enloquecida de amor por el toro.

Del origen y desarrollo de la pasión de esta Pasifae del trópico se nos da cuenta en la sección III, incluida la aparente metamorfosis del conejito en «mozo pervertido» (p. 139), a cuyo deseo corresponde Maité con alegre premura, por el momento olvidada de la prohibición del padre:

Potencializó de tal modo este deseo, que ella, echando a un lado la amenazante visión de su padre, con ufanía se rasgó el vestido. Quedó desnuda. Tuvo que amarrar el perro. Una música agreste impregnó la escena de luz y buenos olores y redujo para siempre el espacio que mediaba entre ellos. Tras el breve forcejeo creyó oírle:

-Lo que nos hace falta, Maité, es no separarnos jamás. ¿Quieres tú? Decíalo con acento entre mojigato y atrevido. Ella meditó: «¿Es legítimo este querer? ¿Es cristiano?» Y parece que le respondieron:

«Tómalo! Es tu bienquerer, Maité.»

Manaba felicidad de una cicatriz oculta (p. 140).

La última, breve Sección IV, contiene la consumación de la catástrofe de esta pequeña tragedia: la huida aterrada de Ulán, vuelto a su forma animal, y la desolación —que tiene algo de expiación-y muerte de Maité. El autor realiza aquí una síntesis - tanto más admirable cuanto lo sintético no es el fuerte de Labrador - desplegando ante el lector la realidad física del conejo, la loca fantasía de Maité vista ahora desde la perspectiva de su desastroso final y, a la vez, el penoso estado de la finca, cuya ruina obra a modo de emblema del destino de Maité.

El comentario de un vecino, con que termina la narración, alcanza el carácter de resumen coral de aquella vida consumida en su solitario laberinto:

...Y como siempre le dio la ventolera a Maité por estalse sola en grima, ¿no será que ya lalgó el piojo, la muy ostiná... y ái la tenemo, tendía..., pudréndose, ella solita? 
En «El gallo en el espejo», finalmente, se nos presenta la luz enfrentada con la sombra, como la guerra de lo espiritual contra lo material y mezquino, de la limpia humildad contra la vileza que la rodea y amenaza. De un lado tenemos a la gallega María Bidó, «todavía muchacha de servir a los sesenta años» (p. 105), y del otro, un mundo de hampones, jóvenes delincuentes duchos en el robo y todo género de picardía, incluido el tráfico menudero de drogas (aparecen también, brevemente, dos auténticos traficantes, sugerencia de más amplios círculos de corrupción, aspecto del que me ocuparé en seguida). En el centro está Guachi, el hijo de María Bidó, a punto de caer en la tentación, siempre renovada por aquellos bribones, sus «amigotes». "Alguna aventurilla le ha tentado; no ha caído», se nos dice al principio (p. 102). Y junto a Guachi, imagen que es su reflejo en más de un sentido, el gallo del título, el pollón de María Bidó, a quien ésta trata y cuida como hijo, en una relación vicaria que la ausencia del hijo - escapado de la casa en parte «porque le fastidia ser gravoso a su madre» (p. 102) - no hace sino reforzar.

El escenario del relato se extiende desde el centro de La Hibana a lejanas zonas arrabaleras, pasando por la intermedia del viejo <mercado único», especie de encrucijada hacia los barrios más apartados, a'gunos de clase media y acomodada, otros de clase obrera, con habitaciones de gran modestia o definitiva miseria, como Luyanó o Jacomino, áreas donde se habrán de situar los llamados El Moro y La Lira en la narración.

El mercado funciona, dentro de esta variada topografía urbana, también como una encrucijada para Guachi mismo, lugar crítico en el cual se está decidiendo su destino. Guachi ha resistido, resiste aún al comienzo, las burlas y pinchazos de «los amigotes que merodean por el mercado», pues aspira a «sacar carretilla, con viandas o frutas (...) así que tenga para el fondo y la garantía» (p. 103). Ahora bien, su actual situación de paria (come lo que se le presenta, duerme en los portales), pese a sus mejores intenciones ( $« \ldots$ él desea ganarse la vida honradamente y cumplir, cumplir siempre» [p. 103]), lo inclinará a considerar la opción que le sugieren a cada momento los «amigotes», la de conseguir dinero fácil, robándolo si no hay otro recurso: «Guachi: te viene bien abril una puelta... No te vas a pasal la vida esperando que te caiga del cielo» (p. 102).

En efecto, el viaje que emprende Guachi a casa de su madre con el fin de buscar unos zapatos con que reemplazar los que lleva, rotos a más de molestos - le han hecho una ampolla en el calcañar, detalle que posee, como tantos otros del texto, valor simbólico-, representa a la vez el descenso del personaje a los «bajos fondos» de su conciencia, pues de modo vagamente formulado, considera la posibilidad de robarle a su madre (doble abyección) tal vez el pollo, tal vez las monedas que guarda en el 
colchón. Los imprevistos que ocurren al final transforman, sin embargo, el viaje en un regreso al hogar, a la acogedora ternura de la madre, que es, al cabo, para Guachi, un retorno a la pureza original. No es, pues, accidental, que la acción se desarrolle la víspera de Nochebuena, con el correspondiente simbolismo de esperanza y renovación, de manera muy particular porque el confuso móvil de Guachi ha sido saquear la casa de su madre para aportar algo al banquete que preparan los amigotes. El bullanguero despliegue - exceso de la gula, bailes verbeneros, ebriedad disfrazada de alegría - con que solía celebrarse la Nochebuena en Cuba queda trascendido en el espiritual desenlace de la «historia», donde reluce el sencillo dar o darse a los otros, don de caridad que ejemplifica a la perfección María Bidó. En cuanto a María Bidó, tampoco es un pormenor casual que al personaje, en su primera aparición, se le sitúe en el Parque Trillo, en el viejo centro cívico de la ciudad, no lejos del Capitolio y el Palacio Presidencial, como si su presencia allí sirviera para proyectar el simbolismo de su figura sobre el latrocinio, venalidad e injusticia que dimanan -corrupción de arriba abajo- de aquellos focos de poder. Con María, siempre, en aquel lugar de su diario descanso, el gallo, el hijo putativo, con una patica «trastornada» a la cual ha aplicado ella una «bizma» semejante a la que ofrece al hijo al final.

Esa cojera del gallo, que refleja la cojera de Guachi — cojera física donde se reflejan, a su vez, los «malos pasos» en que anda Guachi-, necesitada de atención y cura, añade nuevos trazos al diseño simbólico del relato. Pero aún hay más: el gallo, según descubrimos cerca ya del final, «se portaba como persona mayor, se miraba en el espejo» (p. 115); aquel curioso hábito del gallo adquiere pronto otros matices de significación cuando se nos aclara que «jamás cantó ante el espejo a no ser el dî́ que quisieron robarle a ella unas faneguitas de maíz para hacer rollón» (p. 116). El gallo se contempla al espejo, concluimos por asociación de ideas, como una «persona mayor» se asoma al «espejo» de su conciencia, avisando (o avisándose) del mal que allí se anuncia, que desde allí se observa venir. El gallo canta, en fin, anunciando el peligro en que se halla Guachi frente a la casa de la madre al ser interrogado por unos policías de la secreta; los policías lo creen cómplice en la venta de marihuana de uno de sus amigotes. Ahora bien, lo que el gallo anuncia es, también, el peligro en que se encuentra Guachi de caer, en la acepción moral, o más lata, del concepto.

Lo que sobreviene, la escena en que María lo salva de los guardias, salvándolo, a la vez, de todo posible mal, se convierte, por los detalles que allí concurren, en una enfática coda al emblematismo del relato: así, el ofrecimiento de la «bizma» para el pie del hijo, el llanto purificador de 
Guachi y, muy en particular, la dádiva que hace María a Guachi de los pesos plata que guardaba en la colchoneta y que éste desprecia sin decir palabra («Guachi no tocó aquella plata», nos dice el narrador: p. 117). Las tres imágenes que se desarrollan ante nuestros ojos en seguida semejan un crescendo donde cada parte añade otro tono, intensificando el significado previo; procedemos del abrazo protector al hijo (que no cesa de llorar), con el gallo como enlace o mediador, a las monedas que se esparcen por el suelo y, por último, al picoteo del gallo sobre las monedas, al mismo tiempo desdén por el «vil metal» y suerte de bendición por no haber podido obrar «maleficio» sobre Guachi:

Y poniendo el gallo entre su pecho y el pecho de su hijo, le penetró tal alegría y dejadez que las monedas cayeron al suelo, desparramándose. Luego el gallo las fue signando distraídamente con su pico en una ceremonia incomprensible (p. 117).

Ya hemos visto el importante papel que en los relatos de Labrador Ruiz juegan los diálogos o las transcripciones del monologar de los personajes. Constituyen, en verdad, el principal procedimiento de caracterización en las narraciones de Labrador. En «El gallo en el espejo» el procedimiento es, además, esencial a la textura del relato (llamo aquí textura a los distintos planos de significación que se entrelazan para componer el sentido del todo). Los diversos mundos o submundos de la realidad habanera que se nos presenta vienen dados por la forma de expresión correspondiente; muy pocos son los pormenores complementarios que ofrece el narrador para situarnos en uno u otro ambiente. (De esa que podría considerarse fidelidad magnetofónica — compleja habilidad de Labrador que no hay que confundir con las imitaciones de sainete - surge cierta dificultad para el lector, sobre todo el lector extranjero.) Me parece digno de elogio, en este caso, el mosaico que forman las varias jergas del relato: germanía de delincuentes y traficantes de drogas, habla «galifarda» de María Bidó, conversación trivial de muchachas barrioteras, interpelación de los policías enmascarados y aun la carta de declaración en gallego del evaporado esposo de María y padre de Guachi.

Se me ocurre, en fin, que Guachi y su madre se alzan sobre el medio amenazante - figuras tristemente heroicas - del mismo modo que Labrador Ruiz se alzaba, en constante rebelión, contra las sordideces que le rodearon y rebajaron sin cesar su trabajo creador, su orgullosa dedicación a la obra. Esta ha sido la gran virtud de Labrador, pero, irónicamente, a la vez, el lastre que impidió que su obra alcanzara su plena realización. De ahí que sus novelas «gaseiformes» produzcan, francamente, la impresión de cajones de sastre, textos que oscilan entre el lirismo y el ensayismo 
agresivo, sin conseguir jamás el centro armonizador; ese lirismo, por otra parte, dio buenos resultados en Trailer de sueños, así como hoy nos parecen deliciosas defensas a puros puños contra la vida «cultural» cubana de los treinta y los cuarenta sus libros de ensayo: Manera de vivir y Papel de fumar.

La etiqueta de «precursora» para una obra de arte siempre me ha parecido absurda, y aun injusta, por lo que supone de inferioridad respecto a otra hecha después (una comparación doblemente odiosa por basarse en la sucesión cronológica); sin embargo, hay que ver en la obra en general de Labrador Ruiz, dadas las limitaciones de su particular circunstancia, un ambicioso proyecto por desgracia manqué. Y es inevitable, pues, considerar esta obra como una avanzada necesaria para el advenimiento en Cuba de empresas novelescas más consistentes. De cualquier modo, ahí están La sangre hambrienta (desigual, sí, pero con hallazgos brillantes) y un buen número de relatos que han fijado, con genio único, rasgos, momentos, personas, escenarios de una Cuba que es ya pasado, historia, pero que es también suma del carácter colectivo y, por ello, en definitiva, permanencia, poso, «intrahistoria». 
